\title{
CARBON DIOXIDE-PROTEIN INTERACTION IN A GAS-SOLID PHASE
}

\author{
Hisateru Mrtsuda, ${ }^{1}$ Fumio KawaI, ${ }^{2}$ Aijiro Yamamoto, ${ }^{1}$ \\ and Kenji NAKAJIMA ${ }^{1}$ \\ ${ }^{1}$ Department of Food Science and Technology, Faculty of Agriculture, \\ Kyoto University, Kyoto \\ ${ }^{2}$ Laboratory of Food Science and Technology, Research Institute for \\ Production Development, Kyoto
}

(Received May 17, 1975)

Summary In the course of developing the packaging of protein foods under the carbon dioxide atmosphere, various proteins in a solid state were found to adsorb carbon dioxide gas gradually. The results obtained by the Warburg manometry indicated that $100-1,000 \mu 1$ of carbon dioxide gas was adsorbed at $25^{\circ} \mathrm{C}$ for $24 \mathrm{hr}$ by gram of purified proteins, dried protein foods and other proteinous materials such as the rabbit hair and raw silk when they were placed in the high partial pressure of carbon dioxide gas. Casein, gelatin and raw silk were revealed to be the better adsorbents comparing with egg albumin, hemoglobin, gluten and others tested in this experiment. This adsorption was found to be almost specific to carbon dioxide gas. Amount of carbon dioxide gas adsorbed by casein and gelatin depended on the moisture content of them. The lower the moisture is, the greater the adsorption amount of carbon dioxide gas increase. Peptones and partial hydrolyzates of gelatin also showed the adsorbability. Oligo-peptides, amino acids and amines were examined too. Among these, L-lysine (free base), L-arginine (free base), histamine and tyramine adsorbed a large amount of carbon dioxide gas while others failed to do so. Some differences, however, were observed between temperature dependence and reversibility of the carbon dioxide gas adsorption by proteins and those by amines and amino acids (free bases). The mode of interaction between carbon dioxide and protein in a gas-solid phase was discussed comparing with the results obtained in a gas-liquid phase. Large contribution of physical adsorption and less contribution of chemical reaction or chemisorption were assumed in the mode of the carbon dioxide-protein interaction.

It is generally recognized that protein is one of the nutrients that is in critical

1 満田久輝， ${ }^{2}$ 河合文雄， ${ }^{1}$ 山本愛二郎， ${ }^{1}$ 中島謙二 
supply as the demands for meeting the needs of an ever-increasing population intensity. The authors have carried out detailed researches in utilizing microbial cells as a source of protein for improving the world's protein food supply in the future (1).

Microbial isolated proteins (MIPRON) will be used in future as a raw ingredient such as dried egg white and defatted soybean meals. They should have the good properties such as high solubility, mild odor, low bacterial count, good qualities for the processing and so on. The major problems faced in the preservation of these protein foods have been the development of mold growth, discoloration, loss in texture and spring of unpleasant odor. Mold growth and oxidative deterioration are known to take place primarily in the presence of oxygen. In addition to this, many investigators have reported that dehydrated protein foods were very susceptible to the attack by the molecular oxygen $(2,3)$. The obvious solution to these problems would appear to be the packaging and preserving them in the absence of oxygen. In other words, inert gas preservation is effective to retain the qualities. Carbon dioxide has been found to have preservative properties at higher pressures than normally encountered in the atmosphere.

The authors discovered the carbon dioxide gas adsorption phenomenon of cereal grains and developed a novel technique for skin-packaging, the Carbon Dioxide Exchange Method (CEM) $(4,5)$. The principle of this technique bases on the physical adsorption phenomenon of carbon dioxide gas by cereal grains. Examinations of this adsorption phenomenon indicated the possibility of the contribution of capillary condensation at the porous parts of cereal grains (5). In the course of developing the CEM skin-packaging of protein foods, an additional fact was found that dried protein foods and other proteinous materials also adsorb a fair amount of carbon dioxide gas. In this paper, the results obtained by the CEM skin-packaging test of protein and the Warburg manometry on the carbon dioxide gas adsorption by proteins are reported and the mode of interaction between carbon dioxide and protein is discussed.

\section{EXPERIMENTAL}

Materials. All materials used in this study were in a solid state. Whole milk was obtained from Meiji Milk Products Co., Ltd. Hydrocarbon-assymilating yeast was presented by Kyowa Hakko Kogyo Co., Ltd. Raw silk was obtained from the Yokohama Raw Silk Inspection Office. Chinese white rabbit hair was obtained from FPEC Ltd. Rice bran was purchased from local rice dealer's shop. Amino acid mixture which was specially presented by Tanabe Seiyaku Co., Ltd. was prepared by mixing the individual amino acid powder in proportion to the amino acid composition of casein (17). Partial hydrolyzates of gelatin were prepared at the Institute from gelatin powder which was purchased from Yasu 
Kagaku Co., Ltd. Gelatin was partially hydrolyzed with pepsin and trypsin and then the hydrolyzates were fractionated by filtration through the Diafilter and lyophilized. The molecular weight of fraction $\mathrm{A}$ was assumed to be lower than 1,000 , fraction $\mathrm{B}$ to be between 1,000 and 10,000, and fraction $\mathrm{C}$ to be higher than 10,000. Bleached cells of Chlorella were prepared in our laboratory by the method described previously (1). Polypeptone (product of Daigo Eiyo Kagaku Co., Ltd.), Kyokuto-peptone (product of Kyokuto Seiyaku Kogyo Co., Ltd.), bactopeptone and bacto-tryptone (products of Difco Laboratories) were those which were prepared especially for use in bacteriological culture media. Other materials used in this experiment were all purchased from Nakarai Chemical Ltd. and Sigma Chemical Ltd. They were used without purifing furthermore.

Helium, nitrogen, hydrogen, oxygen, ethylene and liquid carbon dioxide cylinders were commercially obtained and used without any purification. Carbon dioxide were $99.95 \%$ purity and less than $0.05 \%$ moisture.

Methods. The Warburg manometric method was used for measuring the adsorption and desorption of carbon dioxide gas by protein. One gram of dried protein is placed in the manometric flask of about $18 \mathrm{ml}$ in volume and air in the flask was purged out by carbon dioxide gas derived from the cylinder. After thermal equilibrium has been achieved, usually after $5 \mathrm{~min}$, the vessel was closed off from the atmosphere and the pressure in the system was measured at intervals of an hour. In this experiment, two manometers were used in carbon dioxide gas atmosphere and one was in air for each sample in addition to an empty thermobarometer which was used to measure the changes in temperature and barometric pressure. The volume of carbon dioxide gas adsorbed (at standard temperature and pressure, STP) per unit weight perr $24 \mathrm{hr}$ was calculated by substracting the value of air manometer from a mean value of carbon dioxide gas manometers.

Protein samples with various moisture content were prepared by equilibrating them for 3 to 14 days in the desiccators with saturated solutions of $\mathrm{LiCl}, \mathrm{K}_{2} \mathrm{CO}_{3}$, $\mathrm{Mg}\left(\mathrm{NO}_{3}\right)_{2}, \mathrm{NaCl}$ and $\mathrm{KNO}_{3}$ at relative humidities between 11 and $88 \%$. Moisture content of them was determined in an air-oven at $105^{\circ} \mathrm{C}$.

\section{RESULTS}

\section{CEM skin-packaging of protein foods and others}

Packaging and preservation tests have been carried out in order to find the usefulness of the CEM technique which was developed during the packaging and preservation of cereal grains. Various protein such as herring roe, shrimp, " $F u$ " (light cake of wheat gluten), gelatin powder, casein powder, silk, woolen cloth and so on were packaged with plastic laminated film under the carbon dioxide gas atmosphere. The packages thus obtained became skin-tight when these materials were packaged with the carbon dioxide gas. In Fig. 1, skin-tightness of CEM packages was compared with it of the conventional ones. Most typical 
difference could be seen in the packages of dried "Fu." As the interesting fact, not only the protein foods but also pure protein powder, animal fibers and their products were packaged skin-tightly by the CEM technique. These findings led us to examine the mode of interaction between carbon dioxide gas and protein. The CEM skin-packages were preserved at room temperature or $4^{\circ} \mathrm{C}$ in a refrigerator for several weeks. Some typical CEM skin-packages that resulted in improved product preservation were shown in Fig. 2. Boiled and dried larval anchovy, shrimp and herring roe packaged by the CEM technique were revealed to retain their original colors and appearances, while those packaged by the conventional method lost their original qualities. Color changes of raw silk during the preservation was retarded in the case of CEM skin-package.

\section{Adsorption of various gases by protein}

In Fig. 3, gas volume adsorbed by casein was plotted against time in hours. As shown in this figure, carbon dioxide gas was adsorbed more than $500 \mu \mathrm{l} / \mathrm{g} / 24 \mathrm{hr}$ while ethylene and oxygen were less than 200 and $50 \mu \mathrm{l} / \mathrm{g} / 24 \mathrm{hr}$ respectively. Approximate equilibrium was obtained after $24 \mathrm{hr}$. Helium, nitrogen, hydrogen and air were also examined but none of them was adsorbed considerably by casein under the same conditions in the case of carbon dioxide gas.

\section{Adsorption of carbon dioxide gas by protein}

Adsorption of carbon dioxide gas by protein was investigated by the Warburg manometry. The amount of carbon dioxide gas adsorbed by protein was shown in Table 1. Various proteins were found to adsorb carbon dioxide gas when they were placed in the high partial pressure of the gas concerned. Simple protein such as egg albumin, zein, gelatin and conjugated protein such as casein (phosphoprotein), hemoglobin (chromoprotein), protein foods and proteinous materials showed the similar behavior to the carbon dioxide gas. Casein, gelatin and raw silk were revealed to be the better adsorbents comparing with others.

\section{Adsorption of carbon dioxide gas by protein hydrolyzates}

As shown in Table 2, various protein hydrolyzates which have been prepared by hydrolysis of protein with proteinases were revealed to adsorb the considerable amount of carbon dioxide gas. Amounts of carbon dioxide gas adsorbed by peptone and tryptone which were obtained from various companies were almost the same except one, bacto-peptone (Difco). In the series of gelatin partial hydrolyzates, the adsorption amount seemed to be in inverse proportion to the molecular weight of them.

\section{Adsorption of carbon dioxide gas by amino acids, peptides and amines}

Naturally occuring amino acids have been tested for their ability of the carbon dioxide gas adsorption. The results were shown in Table 3. Amino acid mixture which was composed of the casein-like pattern of amino acids adsorbed about 


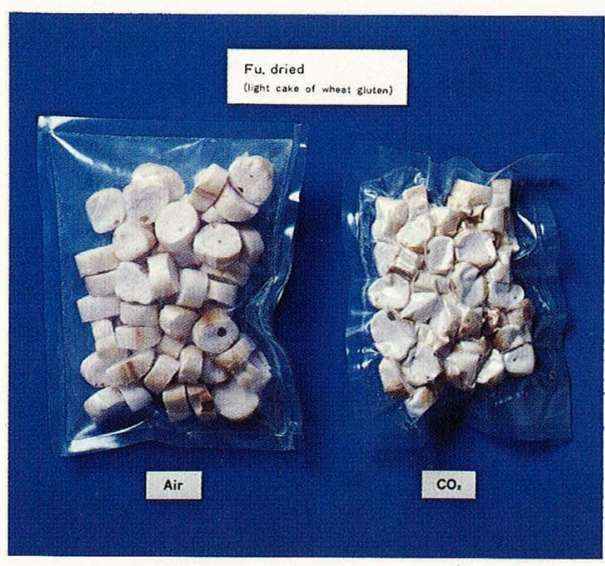

(A)

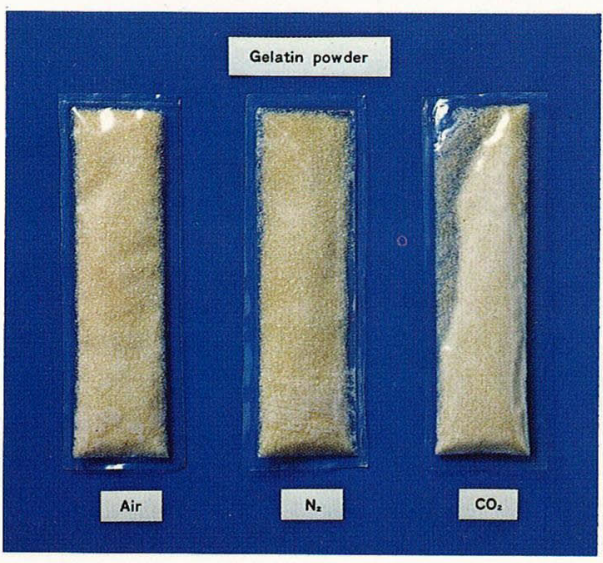

(C)

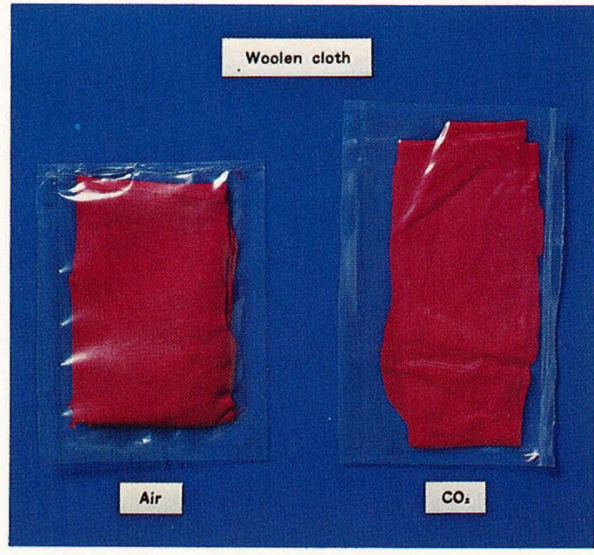

(B)

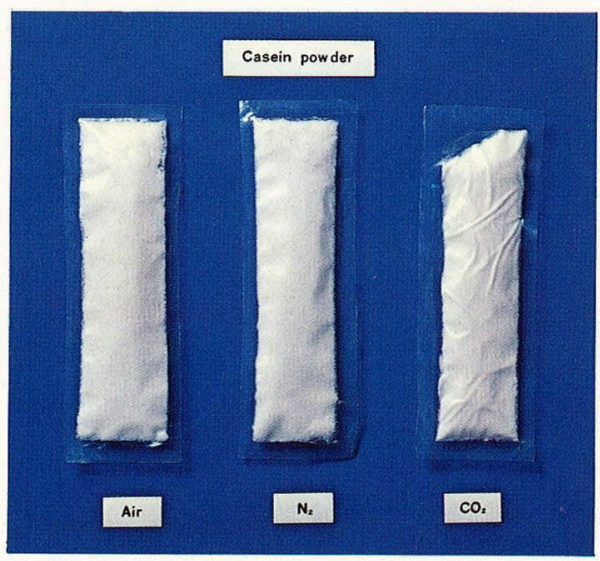

(D)

Fig. 1. Comparison of the skin-tightness of the packages. Left and middle, conventional packages; right, CEM skin-packages, Materials, (A) Fu, dried (light cake of wheat gluten), (B) woolen cloth, (C) gelatin powder, and (D) casein powder. 


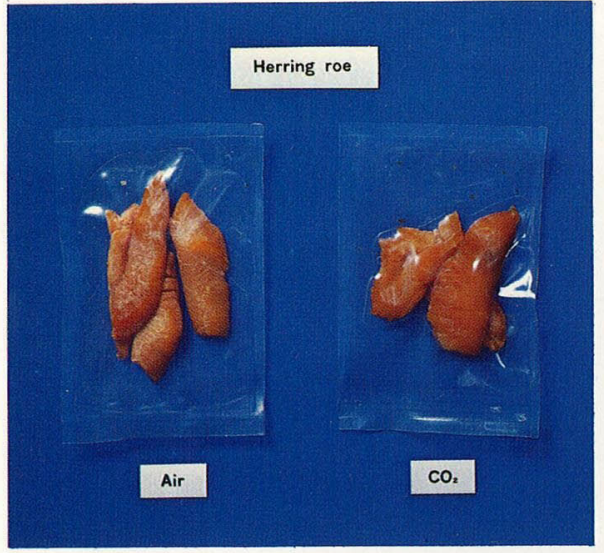

(A)

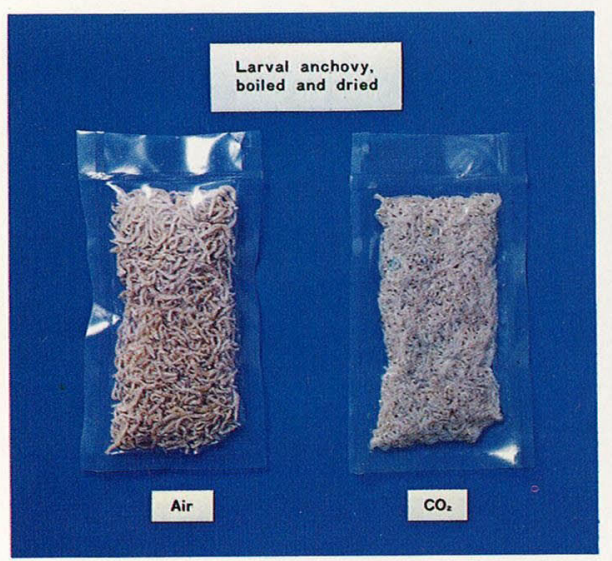

(C)

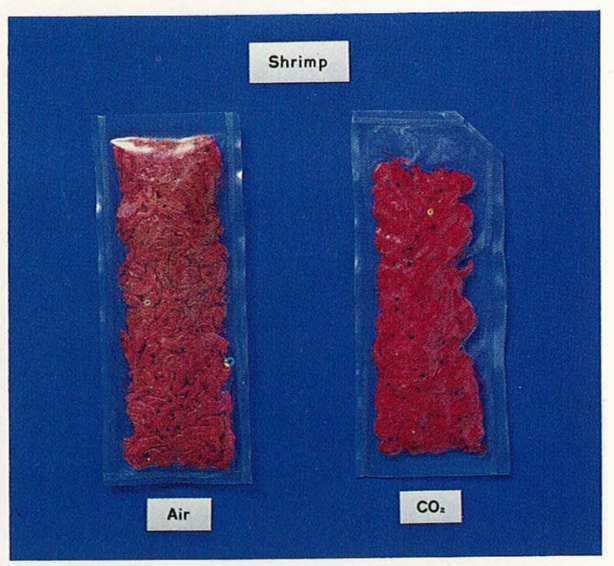

(B)

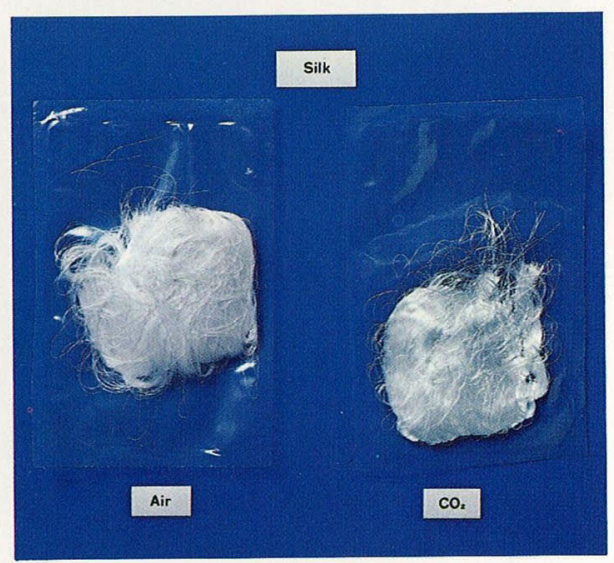

(D)

Fig. 2. Some CEM skin-packages that have resulted in improved product preservation. Left, conventional packages; right, CEM skin-packages. Materials, (A) herring roe, (B) shrimp, (C) larval anchovy, boiled and dried, and (D) silk. 


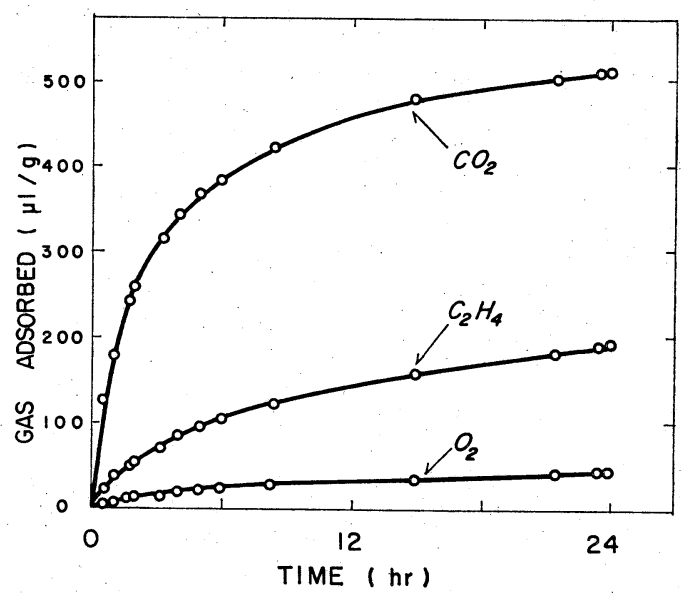

Fig. 3. Adsorption rate of various gases by casein determined by the Warburg manometry at $25^{\circ} \mathrm{C}$.

Table 1. Adsorption of carbon dioxide gas by dried proteins.

\begin{tabular}{lc}
\hline \multicolumn{1}{c}{ Proteins } & $\mathrm{CO}_{2}$ gas adsorbed $^{\mathrm{a}}$ \\
\hline Casein & $662 \mu \mathrm{l} / \mathrm{g}$ \\
Gelatin & 532 \\
Egg albumin & 267 \\
Glutenine & 231 \\
Hemoglobin & 182 \\
Zein & 150 \\
Soybean flour & 220 \\
Whole milk & 200 \\
Bleached Chlorella algae & 163 \\
Hydrocarbon-assimilating yeast & 115 \\
Gluten & 111 \\
Rice bran & 109 \\
Raw silk & 690 \\
Fibroin, from silk & 110 \\
Chinese white rabbit hair & 106 \\
\hline
\end{tabular}

a Determined by the Warburg manometry at $25^{\circ} \mathrm{C}$ for $24 \mathrm{hr}$.

$120 \mu \mathrm{l} / \mathrm{g} / 24 \mathrm{hr}$ of carbon dioxide gas. This value is obviously lower than that adsorbed by casein itself. Among the amino acids tested, L-lysine and L-arginine (free bases) were found to adsorb more than $200 \mu \mathrm{l} / \mathrm{g} / 24 \mathrm{hr}$ of carbon dioxide gas while other amino acids listed in the Table could not do so. Although L-lysine and L-arginine adsorbed carbon dioxide gas when they were used as free bases, they didn't adsorb the gas when they were used as the salts of $\mathrm{HCl}$ or L-glutamate. This implied that free $\varepsilon$-amino groups of L-lysine and guanidino-groups of L-arginine were essential to show the carbon dioxide gas adsorption. Other amino acids such as DL- 
Table 2. Adsorption of carbon dioxide gas by dried protein hydrolyzates.

\begin{tabular}{cc}
\hline Materials & $\mathrm{CO}_{2}$ gas adsorbed \\
\hline Polypeptone (Diago) & $470 \mu \mathrm{l} / \mathrm{g}$ \\
Peptone (Kyokuto) & 324 \\
Bacto-tryptone (Difco) & 392 \\
Bacto-peptone (Difco) & 53 \\
Gelatin hydrolyzates & \\
A & 891 \\
B & 502 \\
C & 297 \\
\hline
\end{tabular}

a Gelatin hydrolyzates were prepared by partial hydrolysis with proteinases and they were fractionated by filtration through Diafilter and lyophilized. Molecular weight assumed are: (A) lower than 1,000, (B) between 1,000 and 10,000, (C) higher than 10,000 .

Table 3. Adsorption of carbon dioxide gas by dried amino acid, peptide and amine powders.

\begin{tabular}{lc}
\hline \multicolumn{1}{c}{ Materials } & $\mathrm{CO}_{2}$ gas adsorbed \\
\hline Amino acids & $119 \mu \mathrm{l} / \mathrm{g}$ \\
Amino acid mixturea & 1,217 \\
L-Lysine & $-21^{\mathrm{b}}$ \\
L-Lysine·HCl & 213 \\
L-Arginine & 9 \\
L-Arginine $\cdot$ L-glutamate & $-15^{\mathrm{b}}$ \\
L-Arginine $\cdot \mathrm{HCl}$ & 22 \\
L-Glutamic acid & 20 \\
L-Cystine & 5 \\
L-Cysteine & \\
Peptides & 75 \\
Glutathione & 55 \\
Glycylglycylglycine & 134 \\
Glycylglycylglycylglycine & \\
Amines & 10,167 \\
Histamine & 537 \\
Tyramine & \\
\hline
\end{tabular}

a Amino acid mixture was patterned after the amino acid composition of casein (17).

b Negative value means that the value obtained from $\mathrm{CO}_{2}$ gas manometer is higher than that from air one under the condition described in EXPERIMENTAL.

methionine, L-leucine, L-histidine (free base), L-tryptophan and L-tyrosine didn't adsorb carbon dioxide gas.

As for the peptides, glycylglycylglycylglycine showed the largest value of the carbon dioxide gas adsorption and glycylglycylglycine followed it while glycyl glycine and glycine didn't adsorb.

Among the amines, histamine adsorbed an extensive amount of carbon dioxide gas. Tyramine also adsorb more than $500 \mu \mathrm{l} / \mathrm{g} / 24 \mathrm{hr}$ while L-glutamine, Lasparagine and $\gamma$-amino- $n$-butyric acid didn't do so. 
Dependence on moisture content of the carbon dioxide gas adsorption by protein

In Fig. 4, the amount of carbon dioxide gas adsorbed by casein and gelatin have been plotted against the moisture content of them. Gas volume in this figure was shown on dry weight of sample while it was shown on wet weight in other figures and tables. The lower the moisture is, the greater the adsorption amount of carbon dioxide increases.

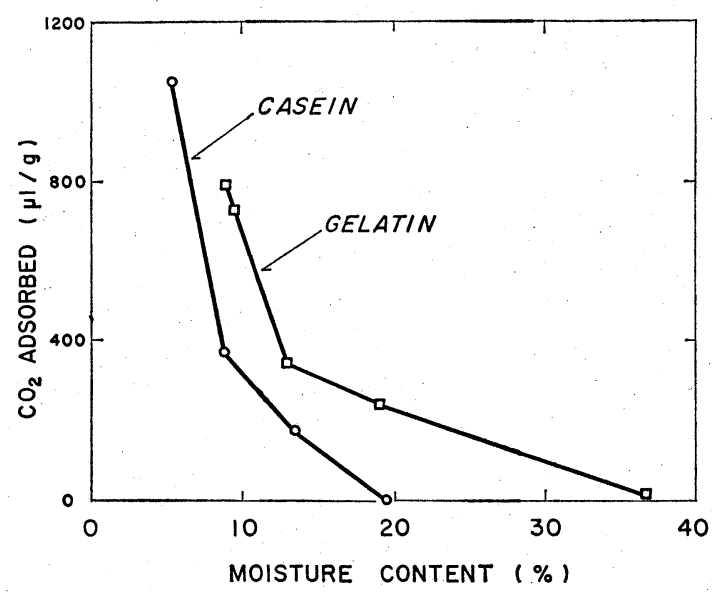

Fig. 4. Effect of moisture content on the amount of carbon dioxide gas adsorbed by casein and gelatin.

\section{Reversibility of the carbon dioxide gas adsorption}

Reversibility of the carbon dioxide gas adsorption by casein, gelatin, L-lysine (free base), L-arginine (free base) and histamine was examined. More than $90 \%$ of carbon dioxide gas which had been adsorbed by casein and gelatin desorbed when they were put into the atmosphere of low partial pressure of carbon dioxide but only a few per cent desorbed in the case of amino acid (free base) and histamine.

\section{DISCUSSION}

The studies on the carbon dioxide-protein interaction have been done mainly in a gas-liquid phase and a few report was presented about the studies in a gassolid phase. In some cases, the results obtained in a gas-liquid phase might be applied to those in a gas-solid phase.

In a gas-liquid phase, carbon dioxide is thought to combine with free amino groups of proteins. This has been demonstrated with hemoglobin (7), and it is possible that the inhibition of plant succinic oxidase by high partial pressure of carbon dioxide ( 8 ) occurs by an analogous mechanism. Catalatic activity was also reported to be sensitive to carbon dioxide. The probability that the inhibition was due to the action of unhydrated and unionized carbon dioxide, 
was presented by using carbonic anhydrase (9). According to Roughton (10), reaction of carbon dioxide with ammonia, and primary and secondary amino groups of aliphatic amines, amino acids and proteins,

$$
\mathrm{RR}^{\prime} \mathrm{NH}+\mathrm{CO}_{2} \rightleftarrows \mathrm{RR}^{\prime} \mathrm{NCOO}^{-}+\mathrm{H}^{+}
$$

is rapid, more rapid than the hydration of carbon dioxide to carbonic acid, and requires no catalyst. Direct reaction occurs only with uncharged amino groups. Reaction species were reported to be $\mathrm{CO}_{2}$, and there was no evidence that carbonic acid, bicarbonate, or carbonate reacted directly with amino groups.

In a gas-solid phase, carbon dioxide gas has been thought to be absorbed by almost any product that conteins moisture. Growe examined a "snugging effect" of the film which was produced by carbon dioxide gas packaging, and estimated that it is caused by the hydration of carbon dioxide gas (11). The reaction is: $\mathrm{CO}_{2}+\mathrm{H}_{2} \mathrm{O} \rightleftarrows \mathrm{H}_{2} \mathrm{CO}_{3}$

In this study, Fig. 4 indicates clearly that carbon dioxide gas adsorption depends on the moisture content of samples but the tendency is opposite to that assumed by Growe. This is quite similar to the results obtained in the case of the carbon dioxide gas adsorption by paddy rice (5). This imply that the hydration of carbon dioxide gas is not the main cause of the carbon dioxide gas adsorption by proteins.

The amount of carbon dioxide gas shown in Tables 1,2 and 3 are those which are obtained by the materials tested in the arbitrary moisture content. So the simple comparison of each value doesn't present clear characteristics of their adsorption. It may be, however, quite admitted to consider the tendency which is observed in these values. Peptones and partial hydrolyzates of gelatin tend to adsorb carbon dioxide gas more than proteins and amino acids do. Among the amino acids tested, L-lysine (free base) remarkably adsorbs carbon dioxide gas comparing with peptones and proteins. Amino acid mixture of which composition was designed to be casein and L-arginine (free base) situated on next. Generally free amino groups are expected to contribute greatly to the carbon dioxide gas adsorption by protein, but results obtained in this study cannot be explained directly by the carbamation of free amino groups of protein such as $\varepsilon$-amino group of lysine and guanidino group of arginine and $\alpha$-amino group of all amino acids. Although large amounts of carbon dioxide gas were adsorbed by histamine, tyramine, L-lysine (free base) and L-arginine (free base), temperature dependence of the adsorption was somewhat different from that of protein such as casein and gelatin. The amount of carbon dioxide gas adsorbed by these amines and amino acids (free bases) increased as the temperature increased, while it decreased in the case of casein and gelatin. In addition to this, the carbon dioxide gas adsorbed by amines and amino acids (free bases) was not desorbed even when these materials were placed in the low partial pressure of carbon dioxide in which more than $90 \%$ of the gas adsorbed by casein and gelatin was desorbed. Interaction between carbon dioxide gas and amines and amino acids (free bases) seemed to be "chemical reaction" or "chemisorption" 
rather than "physical adsorption." This may also indicates that reactivity of carbon dioxide with free amino groups in amino acids, peptides, amines and proteins are different with each others in a gas-solid phase. It is reported that amino acid carbamates obtained in a gas-liquid phase are not always stable. On exposure to air at room or at elevated temperatures, they liquefy owing to their hygroscopic nature, and decompose with visible evolution of carbon dioxide gas (12). A little reversibility found in the case of amino acid (free base) and histamine may be caused by this decomposition. Quantitative analysis of amines and free amino groups in the protein samples tested in this study might present another information about the interaction between carbon dioxide gas and proteins.

Dependence on moisture content of the carbon dioxide adsorption by protein calls us attention to the similar interaction between molecular oxygen and dehydrated foods. In the latter case, monomolecular layer of moisture is assumed to prevent the attack of molecular oxygen to the various active groups and free radicals in the dehydrated foods (13).

On the other hand, RIEPE and WANG $(14,15)$ examined the infrared spectra of carbonic anhydrase solutions equilibrated with $\mathrm{CO}_{2}+\mathrm{N}_{2} \mathrm{O}$ mixtures and infered that the $\mathrm{CO}_{2}$ (or $\mathrm{N}_{2} \mathrm{O}$ ) is bound in a hydrophobic cavity of the protein. SCHULTZ and RANDALL (16) reported the interesting paper in which they examined the distribution coefficients for alcohols and esters between the liquid carbon dioxide and water. They stated that as the molecular weight (namely, number of carbon atoms) increase within a homologous series, a greater part of the solute tend to concentrate in the liquid carbon dioxide phase. This higher affinity of liquid carbon dioxide to the carbon chain of alcohols and esters suggests the possibility of hydrophobic interaction between carbon dioxide gas and peptide chain of protein in the carbon dioxide gas adsorption by proteins. A conclusion cannot be drawn due to an insufficient number of experimental samples, results obtained with the carbon dioxide gas adsorption by glycine, glycylglycine, glycylglycylglycine and glycylglycylglycylglycine showed the possibility of this interaction.

\section{REFERENCES}

1) Mitsuda, H., J. Nutr. Sci. Vitaminol., 19, 1 (1973).

2) Sidwell, C. G., Salwin, H., and Koch, R. B., J. Food Sci., 27, 255 (1962).

3) Haller, H. S. and Holm, G. E., J. Dairy Sci., 30, 197 (1947).

4) Mitsuda, H., Kawai, F., Kuga, M., and Yamamoto, A., J. Japanese Soc. Food Nutr., 25, 627 (1972).

5) Mrtsuda, H., Kawai, F., Kuga, M., and Yаmamoto, A., J. Nutr. Sci. Vitaminol., 19, 71 (1973).

6) Mitsuda, H., Kawai, F., and Yamamoto, A., Mem. Coll. Agr. Kyoto Univ., 100, 49 (1971).

7) Wyman, Jr. J., Advances in Protein Chem., 4, 485 (1948).

8) Ramson, S. L., Walker, D. A., and Clarke, I. D., Biochem. J., 66, 57 (1971).

9) Mitsuda, H., Kawai, F., Yasumoto, K., and Hirotani, K., Bull. Inst. Chem. Research, Kyoto Univ., 36, 145 (1958).

10) Roughton F. J. W., Harvey Lect., 39, 96 (1943). 
11) Growe, T. H., Modern Packaging, Oct., 183 (1969).

12) Bailey, J. L., J. Chem. Soc., 1950, 3461.

13) SAlwin, H., Food Technol., 13, 594 (1959).

14) RiePe, M. E. and Wang, J. H., J. Amer. Chem. Soc., 89, 4229 (1967).

15) RiePE, M. E. and WANG, J. H., J. Biol. Chem., 243, 2779 (1968).

16) Schultz, W. G. and Randall, J. M., Food Technol., 24, 1282 (1970).

17) Iтон, H., Kishi, T., ЕмA, M., and ChibatA, I., J. Nutr. Sci. Vitaminol., 20, 431 (1974). 